\title{
A História do Radiodiagnóstico no INCA
}

\section{History of Radiodiagnosis at INCA}

João Carlos Cabral', Amarino Carvalho de Oliveira Júnior ${ }^{2}$

e Darcy da Silva Guimarães ${ }^{3}$

A história do radiodiagnóstico no INCA confunde-se, em muito, com a própria história do Instituto, uma vez que ela nasceu com 0 antigo $C$ entro de $C$ ancerologia, em 1938, criado pelo Decreto Lei no 378 , de 13 de janeiro de 1937.

0 médico Evaristo $M$ achado $N$ eto, formado em 1933 pela Faculdade de M edicina da U niversidade Federal do Rio de Janeiro, um dos fundadores do Serviço $N$ acional de Câncer e do Instituto de Câncer, foi o primeiro a iniciar as atividades laborativas da radiologia no INCA. Após especialização em Viena, e contando com apenas um aparelho Siemens de 100 M A, ele trabalhou gratuitamente, durante dois anos.

Em 1945, passou a receber a colaboração de J oão C arlos Cabral que, ainda como estudante de M edicina e operador de aparelhos de raios- $X$, ingressou, por concurso, no Instituto de Câncer, cuja oficialização se deu por meio do Artigo $2 \div$ do D ecreto Lei no 15.971. Já como 1을 Assistente, João Carlos Cabral passou a ser o substituto de Evaristo $M$ achado $N$ eto nas ausências eventuais deste.

Em 04 de julho de 1946, já o Centro de Cancerologia instalado em dependências da Fundação Gafrée e Guinle, devido ao custo elevadíssimo da aparelhagem e de sua instalação, não houve interesse, na área acadêmica, de jovens para exercerem tão complexa especialidade. M esmo assim, a Seção de Radiodiagnóstico passou a contar com a colaboração dos médicos Benedito Gentil da Silva, Dimar Ferreira Ramos e Claudino Ribeiro e Castro.

Com a transferência do Instituto de Câncer, em 23 de agosto de 1957, para 0 prédio da Praça da Cruz Vermelha no 23, a Seção ficou localizada no 30 andar da ala de frente do prédio.

Em 23 de janeiro de 1961, pelo Decreto 50.251, o Instituto de Câncer passa a ter a denominação oficial de Instituto $\mathrm{N}$ acional de Câncer (IN CA). E logo após, em 1964, com a inauguração do bloco anexo, e já com a denominação oficial de Serviço de Radiodiagnóstico, o setor foi consideravelmente ampliado, passando a ocupar uma área de aproximadamente de $1.000 \mathrm{~m}^{2}$ e a dispor de um aparelho com seriógrafo, dois aparelhos de radiologia geral, um tomógrafo universal e um craneógrafo. Foi também construída uma câmara escura central, um moderno arquivo geral de radiografias, um excelente arquivo nosológico e amplas sal as para o chefe, assistentes e demais colaboradores e técnicos operadores dos equipamentos. N essa ocasião, - Serviço també já contava com o médico Gerson Slobak de Freitas.

A partir de 1980, com a criação da Campanha N acional de Combate ao Câncer, novos médicos foram integrados ao staff do Serviço: João Paulo M atushita, Liane Braga, D ra. M arília Gomes de M ello, Suzana Cavalieri, Carlos Eduardo Lassance Cabral, Eliane Boasquivisque e Luiz Lage Toledo.

$\mathrm{N}$ a década de 80, o Serviço recebeu equipamentos modernos na área da image nologia, como aparelhos de ultra-sonografia (1984) e de tomografia computadorizada (1987), todos já atualmente renovados. Em 1991, o Serviço foi dotado com um equipamento de ressonância magnética, que foi substituído por outro mais moderno, em 1994, que ainda se encontra em funcionamento. 
O Serviço foi totalmente reformado em $1999 / 2000$, e possui atualmente muito mais modernas instalações e equipamentos.

Durante seu início e até o presente momento, sua chefia foi ocupada e sua história foi liderada pelos seguintes servidores médicos: Evaristo M achado N eto (I938/1969), João Carlos Cabral (1970/1978), H ilton Augusto Koch (1979/1985 e 1991/1992), J oão Paulo M atushita (1986/1987), Eliana Boasquevisque (1987/1988), Luiz Lage Toledo (1988/1989), Carlos Eduardo Lassance Cabral (1989/1990 el993/1998) e, desde23 de outubro de 1998, Amarino Carvalho de O liveira Júnior.

Porém, a História do Serviço de Radiodiagnóstico é, mais que a história de um Serviço, a história do próprio Instituto
$\mathrm{N}$ acional de $\mathrm{C}$ âncer. $\mathrm{E}$ dos diretores que 0 conduziram e o conduz: M ário Kroeff (1938/ 1941), Alberto Lima de M oraes Coutinho (1941/1954), Luiz C arlos de O liveira Júnior ( 1954/1956), Antônio Pinto V ieira ( 1956/I962), M oacyr Alves dos Santos Silva (1962/1963 e 1972/1974), Francisco Fialho (1963/1967 e 1969/1970), J orge Sampaio de M arsillac M otta (1967/1969), Ugo de Castro Pinheiro G uiimarães(1970/1972), Adayr Eiras deAraújo (I974/1978), João Carlos Cabral (1978), Wolfgang George Lamprecht (I978/1979), H iran Silveira Lucas (1979//980), Ary Frauzino Pereira (I980//985), Geraldo M atos de Sá (1985/1986), Walter Roriz de Carvalho (I986/ 1990), M arcos Fernando de O liveira M oraes (I990/1998) e Jacob K ligerman (a partir de 1998). 